\title{
A Case of with an Incidental Penetrating Foreign Body in Lumbar 2 Vertebra
}

\author{
Omer Furkan Turkis, Volkan Murat Ünal
}

Department of Neurosurgery, Saglik Bilimleri University, Tepecik Research and Training Hospital, Izmir, Turkey
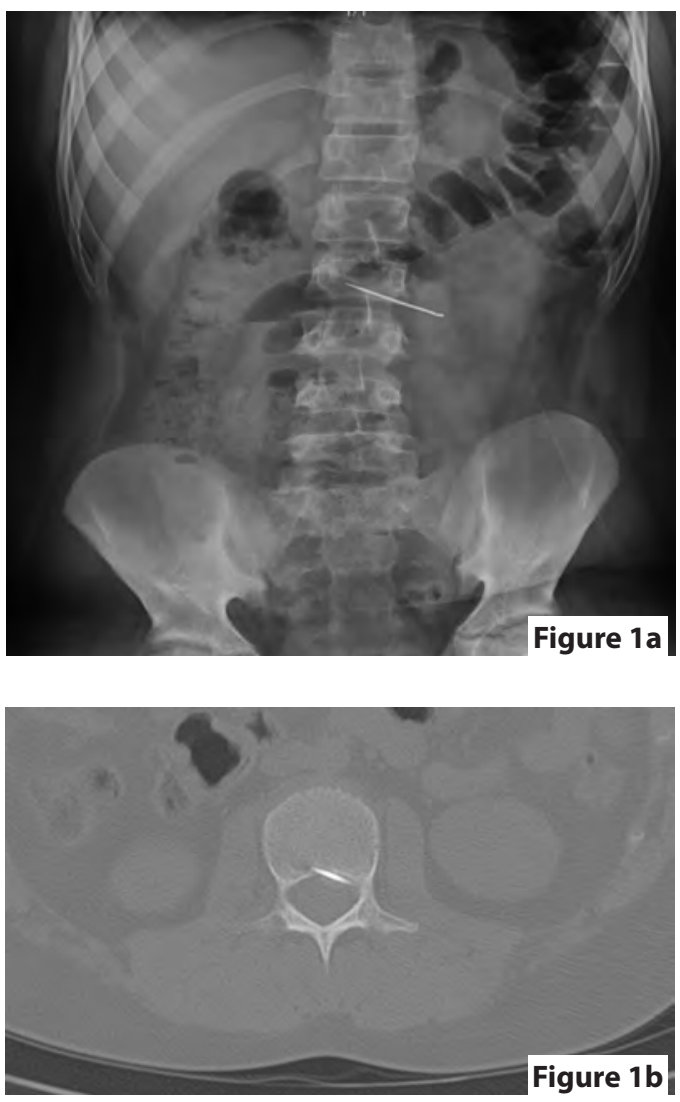

12-year-old male was admitted to the pediatric emergency department with stomach ache. On physical examination the abdomen was normal, the rebound sign was negative, but mild defense was observed. According to standing AP X-ray of the abdomen, a pene-

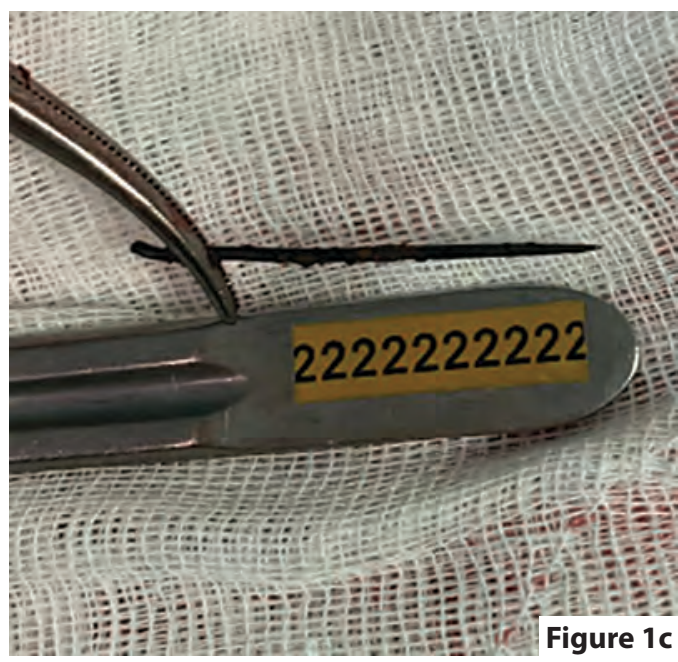

trating foreign body was seen on the left and at the level of the stomach (Figure 1A). The patient was questioned again about swallowing any foreign body or penetrating body access holes on the patient's skin but there was no history of ingestion of foreign bodies or any access hole of a penetrating body observed on the patient's skin. Therefore the patient was hospitalized in the pediatric surgical service. On abdominal computed tomography, the foreign body was seen at the level of the L2 vertebra left pedicle (Figure 1B) and as a result the patient was referred to our clinic (neurosurgery) for surgery. The patient was laid down in the prone position. After L2 level had been determined 
by fluoroscopy, the operation began with a vertical left paramedian incision. After the fascia was cut, the foreign body was sought by fluoroscopy between the paravertebral muscles. When the foreign body was found, it was removed by pulling with a rongeur. It was a rusty nail (Figure 1C). Subsequently, no cerebrospinal fluid was observed and the operation was completed.

Key Words: Foreign Body • Vertebra • Incidental.
Authors' Contributions: Conception and design: ÖFT; Acquisition, analysis and interpretation of data: VMÜ; Drafting the article: ÖFT; Revising it critically for important intellectual content: VMÜ; Approved final version of the manuscript: ÖFT.

Conflict of Interest: The authors declare that they have no conflict of interest.

Correspondence:

omerfurkanturkis@outlook.com

Tel.: + 902324676767

Fax. + 902324330756

Received: 20 December 2018; Accepted: 29 March 2019 